
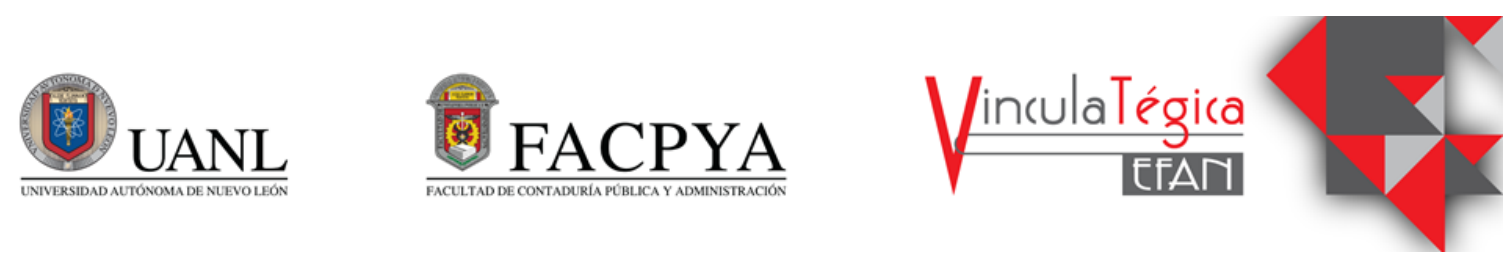

\title{
Factores de la gestión administrativa de empresas artesanales. Un estudio desde la perspectiva de artesanos de un pueblo mágico
}

\author{
Cynthia Monge Santos ${ }^{1}$, Teresa García López y y Daniel Armando Olivera Gómez ${ }^{3}$
}

${ }^{1}$ Universidad Veracruzana, Instituto de Investigaciones y Estudios Superiores de las Ciencias Administrativas mongesantosc@gmail.com, Av.Dr. Luis Castelazo Ayala S/N Industrial las Ánimas, 2288421700 Ext. 13907

${ }^{2}$ Universidad Veracruzana, Instituto de Investigaciones y Estudios Superiores de las Ciencias Administrativas tgarcia3110@hotmail.com, Av. Dr. Luis Castelazo Ayala S/N Industrial las Ánimas, 2288421700 Ext. 13907

${ }^{3}$ Universidad Veracruzana, Instituto de Investigaciones y Estudios Superiores de las Ciencias Administrativas doliverag@hotmail.com,Av. Dr. Luis Castelazo Ayala S/N Industrial las Ánimas, 2288421700 Ext. 13907

Información del artículo revisado por pares

Fecha de aceptación: junio-2021

Fecha de publicación en línea: diciembre-2021

DOI: https://doi.org/10.29105/vtga7.1-138

\begin{abstract}
Resumen
En este trabajo de investigación se toma como objeto de estudio a las empresas registradas en el área de Desarrollo Económico, dedicadas a la actividad de elaboración y venta de artesanías de Coatepec Veracruz, México. El objetivo principal del estudio, fue identificar los factores de la gestión administrativa que aplican dichas empresas artesanales para comprender su funcionamiento y permanencia en el mercado, así como los efectos derivados del virus SARS-CoV-2 en 2020. La metodología desarrollada mediante un enfoque mixto con alcance descriptivo y en el que se manejaron como instrumentos, una guía de entrevista y un cuestionario, permitieron obtener información para identificar los factores de la gestión administrativa practicados por las empresas artesanales antes mencionadas, los cuales fueron: Estrategias administrativas generales; Calidad e Innovación del producto; Gestión de mercadotecnia; Recursos tecnológicos; Competencia; Gestión financiera; y Conocimiento del entorno. Los factores antes mencionados, permitieron tener una visión del funcionamiento de las empresas artesanales, identificando estrategias clave, como las relacionadas a la Calidad y la Innovación en sus productos, la cual consideran como uno de los puntos clave para lograr la preferencia del cliente, vender sus productos a través de redes sociales o
\end{abstract}

\begin{abstract}
In this research work, the companies registered in the Economic Development area, dedicated to the activity of making and selling handicrafts from Coatepec Veracruz, Mexico, are taken as the object of study. The main objective of the study was to identify the administrative management factors applied by these artisan companies to understand their operation and permanence in the market as well as the effects derived from the SARS-CoV-2 virus in 2020. The methodology developed through a mixed approach with a descriptive scope and in which an interview guide was used as instruments, as well as a questionnaire, allowed obtaining information to identify the factors of administrative management practiced by the artisan companies, which were: General administrative strategies; Product Quality and Innovation; Marketing management; Technological resources; Competence; Financial management; and Knowledge of the environment. This factors, allowed to have a vision of the operation of the artisan companies, identifying key strategies, such as those related to Quality and Innovation in their products, which they consider as one of the key points to achieve customer preference., sell their products through social networks, or have points of sale in local and national exhibitions to achieve sales and their permanence. The artisan companies of Coatepec Veracruz, face a competitive market but in their
\end{abstract}


tener puntos de venta en exposiciones locales y nacionales para lograr ventas y su permanencia. Las empresas artesanales de Coatepec Veracruz, se enfrentan a un mercado competitivo, pero en su opinión, un negocio lleno de posibilidades para mejorar y crecer ya que la consideran una oportunidad para el auto-empleo y el desarrollo de actividades que realizan con gusto y entusiasmo.

Palabras clave: Gestión administrativa; Artesanías; Emprendimiento; Cuantitativo.

\section{INTRODUCCIÓN}

En México, las artesanías son una parte de la riqueza cultural del país y se caracterizan por ser artículos hechos a mano que son utilizados en la vida diaria, como vestuario, calzado, ornamentos para uso culinario o decorativo, entre otros usos. Las empresas artesanales son una alternativa para el desarrollo de la sociedad, pues son generadoras de empleo, una oportunidad para emprender y también, permiten aprovechar el potencial creador $\mathrm{y}$ artístico de los individuos.

Las empresas artesanales son sumamente importantes para la economía mexicana, en el año 2016 estas empresas, en su conjunto, presentaron una contribución de $17.8 \%$ del PIB del sector de la cultura, esto es, el $0.6 \%$ del PIB nacional, teniendo una aportación de 110 mil 121 millones de pesos y no sólo eso, igualmente, en 2016, la Cuenta Satélite de la Cultura en México (CSCM) reportó que se generaron 386,601 puestos de trabajo ocupados remunerados, esto es, jornadas de trabajo de 8 horas diarias. De esta manera, en el sector de la cultura, 3 de cada 10 puestos ocupados corresponden a las artesanías (INEGI, FONART \& SEDESOL, 2018).

Otro aspecto a considerar es que México en 2019 de acuerdo a la Organización Mundial para el Turismo, era el número seis en la lista de los países más visitados en el mundo (Méndez, 2019), y cuando mexicanos y extranjeros visitan alguna ciudad o atracción turística de México, una de las cosas que más consumen, son productos hechos por artesanos del país, ya que con este consumo, se llevan el recuerdo de parte de la cultura que lo caracteriza; la adquisición de artesanías opinion, a business full of possibilities to improve and grow since they consider it an opportunity for selfemployment and the development of activities that they carry out with pleasure and enthusiasm.

Keywords: Administrative management; Artisan; Entrepreneurship; Quantitative

JEL: M1.

representa más del 4\% del PIB que genera el turismo en México (El Economista, 2018).

Las empresas artesanales forman parte del sector de Micro, pequeñas y medianas empresas (MIPyME) del país, el cual a través de los años se ha visto afectado por diferentes barreras y limitaciones a las que se enfrentan por su tamaño, entre las que han destacado entre otras, una deficiente administración y cultura empresarial (Luna, Salgado, Cuevas, \& Barrios, 2016). Es por ello, que es importante realizar estudios que permitan tener un conocimiento más claro de la situación de este tipo de empresas en el país, a través de la identificación de los factores de la gestión administrativa que pudieran tener relación en el éxito o fracaso de las mismas.

Por tanto, este proyecto de investigación se orientó a identificar los factores de la gestión administrativa que aplican en su funcionamiento las empresas artesanales de México, tomando como objeto de estudio a un grupo de artesanos de la ciudad de Coatepec, Veracruz.

\section{MARCO TEÓRICO}

Considerando que el tema central de este trabajo fue la gestión administrativa, cabe mencionar que algunos autores plantean que la gestión es: "La medida y el análisis, la visión y la comprensión, para la acción. La medida y el análisis son la base de la acción, puesto que la acción se hace muy incierta si no se puede ver o no se puede comprender" (Lopez \& Arevalo, 2010, pág. 78).

Es entonces la Gestión, aquella que se relaciona con la acción dentro de las organizaciones que permite establecer las directrices que las conducen a un estado superior de acuerdo con su identidad, fines y 
propósitos (Lopez \& Arevalo, 2010).

Es importante mencionar que la gestión no solamente se centra en el manejo de lo interno, sino también de los elementos determinantes del entorno. Así la gestión cumple una función de articulación entre la organización y los demás sistemas del medio y asume la labor de proyección de la organización, para lo cual debe estar en contacto continuo con las variables externas (Lopez \& Arevalo, 2010).

Hoy frente a una actualidad donde las organizaciones cada vez son más complejas, y cada vez son más en el mercado, se necesita no solo de la gestión del proceso administrativo clásico, sino de ver a la gestión administrativa como una herramienta de manera holística que une los elementos internos y externos administrativos para lograr los objetivos de las organizaciones.

\section{MÉTODO}

Con el objetivo de Identificar los factores de la gestión administrativa que practican en su operación las empresas artesanales de la ciudad de Coatepec Veracruz para comprender su funcionamiento $y$ permanencia en el mercado, se diseñó un proyecto de investigación mixto (cualitativo y cuantitativo) con alcance descriptivo y diseño transeccional en el que la población objeto de estudio eran 90 pequeñas empresas artesanales de la ciudad de Coatepec, Veracruz, registradas en el departamento de Desarrollo Económico de la actual administración 2018-2021 de dicho municipio, y que trabajan en los bajos de Palacio Municipal exponiendo sus productos para la venta.

La variable a estudiar se conceptualizó como: Gestión administrativa: enfoque de integración disciplinar que permite una mejor comprensión y manejo de las organizaciones,

Cuadro 1 Operacionalización de la variable Gestión administrativa conduciéndolas a un estado superior de acuerdo con su identidad, fines y propósitos y bajo el cumplimiento de las funciones clásicas del proceso administrativo. (Lopez \& Arevalo, 2010).

Como parte de la metodología, se planeó fundamentar el diseño del instrumento de recopilación de información para el estudio cuantitativo con los resultados cualitativos. Por lo que se elaboró una guía de entrevista semi-estructurada que fue usada en la realización de cinco entrevistas a profundidad a artesanos pertenecientes al grupo objeto de estudio.

Las primeras tres entrevista fueron realizadas antes de la pandemia COVID-19, y las últimas dos entrevistas en diciembre 2020, durante el tiempo de pandemia de COVID2019. Para la selección de los entrevistados, se contó con el apoyo de una de las dirigentes del grupo de artesanos, quien proporcionó información acerca de sus agremiados para la selección de los mismos.

Las características de las tres primeras entrevistadas del género femenino, fueron: la antigüedad y experiencia de más de 10 años de una de ellas; una madre soltera y otra con un producto único y elegante. Para las dos últimas entrevistas, se eligió: a la artesana más joven del grupo (25 años de edad), y a un artesano joven del sexo masculino, de 30 años de edad con más de 10 años en el mercado con sus artesanías.

Para el análisis e interpretación de las entrevistas, se utilizó el software ATLAS.ti y los resultados fueron presentados mediante redes de citas codificadas. Estos resultados, sirvieron como fundamente para el diseño del instrumento de recopilación de información del estudio cuantitativo y las categorías de estudio dieron lugar a la operacionalización de la variable como se muestra en el Cuadro1.

\begin{tabular}{|c|c|c|}
\hline Variable & DIMENSIÓN & INDICADORES \\
\hline \multirow{5}{*}{$\begin{array}{l}\text { Gestión administrativa. } \\
\text { Enfoque de integración } \\
\text { disciplinar que permite } \\
\text { una mejor comprensión y } \\
\text { manejo de las }\end{array}$} & \multirow{3}{*}{$\begin{array}{l}\text { Estrategias } \\
\text { administrativas } \\
\text { generales }\end{array}$} & Identidad organizacional \\
\hline & & Estrategias administrativas generales \\
\hline & & Gestión de Recursos humanos \\
\hline & \multirow{2}{*}{$\begin{array}{l}\text { Calidad e innovación } \\
\text { del producto }\end{array}$} & Calidad del producto \\
\hline & & Innovación del producto \\
\hline
\end{tabular}




\begin{tabular}{|c|c|c|}
\hline \multirow{11}{*}{$\begin{array}{l}\text { organizaciones, } \\
\text { conduciéndolas a un } \\
\text { estado superior de } \\
\text { acuerdo con su identidad, } \\
\text { fines y propósitos y bajo } \\
\text { el cumplimiento de las } \\
\text { funciones clásicas del } \\
\text { proceso administrativo. } \\
\text { (Lopez \& Arevalo, 2010). }\end{array}$} & \multirow{2}{*}{$\begin{array}{l}\text { Gestión de } \\
\text { mercadotecnia }\end{array}$} & Estrategias de mercadotecnia utilizadas \\
\hline & & Motivos para no usar estrategias de mercadotecnia \\
\hline & \multirow{2}{*}{ Recursos tecnológicos } & Recursos tecnológicos utilizados \\
\hline & & Motivos para no utilizar recursos tecnológicos \\
\hline & \multirow{2}{*}{ Competencia } & Conocimiento y estrategias de la competencia \\
\hline & & Situación competitiva \\
\hline & \multirow{2}{*}{ Gestión financiera } & Formalidad \\
\hline & & Estrategias financieras \\
\hline & \multirow{3}{*}{ Conocimiento entorno } & Limitantes del entorno \\
\hline & & Ventajas del entorno \\
\hline & & Efectos covid-19 \\
\hline
\end{tabular}

Este documento refiere los resultados obtenidos de la realización del estudio cuantitativo, por lo que es conveniente mencionar que se utilizó un cuestionario conformado de 30 ítems, los primeros ocho solicitaban datos sociodemográficos como: sexo, edad, estado civil, grado de estudios, producto, permanencia, motivos de emprender, dedicación. A partir del ítem número nueve hasta el treinta, se solicitó información acerca de la gestión administrativa. Con relación al tipo de preguntas usadas, 25 fueron de opciones (dicotómicas y múltiples) y cinco fueron preguntas abiertas.

El alcance del estudio fue descriptivo y su diseño transeccional. Debido a que la recopilación se realizó durante el tiempo de pandemia, la decisión fue realizar una encuesta a los artesanos mediante el cuestionario digital (formulario de Google) y la utilización de WhatsApp; el envío se realizó en diciembre 2020 a través del correo electrónico de la dirigente que apoyaba el proyecto, sin embargo la respuesta tardaba demasiado $y$ fueron pocos los que respondieron.

Sin embargo, a finales de diciembre 2020, permiten nuevamente reanudar las actividades de venta en los bajos del Palacio Municipal y del total de empresas que vuelve a su labor de venta, cumpliendo con todos los protocolos de sanidad y protección, únicamente se presentan 36 , disminuyendo un $60 \%$ el total de la población considerada inicialmente de 90 empresas.

Es por lo antes mencionado que finalmente la información que pudo obtenerse, corresponde a únicamente 26 artesanos que proporcionaron información para el estudio, ya que algunos de ellos, como prevención y protección personal mandó personal contratado para venta, impidiendo tener un contacto directo con el empresario fundador de las mismas, de quien interesaba obtener la información.

La información obtenida, se analizó mediante la tabla de datos diseñada con la información de los cuestionarios de Google aplicados y los recopilados presencialmente. El análisis y la interpretación se realizó mediante la hoja de cálculo de Excel versión 13; el software Statistical Package for the Social Sciences (SPSS) versión 22, y Minitab Versión 20, generando gráficas y tablas con los resultados de mayor relevancia.

\section{RESULTADOS}

Los resultados que se presentan a continuación, se integraron en dos apartados, en el primero, se tiene la descripción de los datos sociodemográficos de los encuestados y en segundo, la descripción de las dimensiones que conformaron la variable Gestión Administrativa mostrada en el Cuadro 1.

\subsection{Datos sociodemográficos}

Se encontró que en el grupo de artesanos de la ciudad de Coatepec Veracruz, hay más mujeres (58\%) que hombres (42\%), sin embargo, de acuerdo con la prueba de Fisher en su p-value $=0.406$ señaló que no existe diferencia significativa entre ambas proporciones.

En cuanto, a la edad el artesano de mayor edad del grupo tenía 65 años de edad, y los más jóvenes 25 . El promedio de edad fue de 42.5 años y la mitad de los artesanos tiene entre 25 (mínimo) y 41.5 (mediana) años de 
edad. Los hombres tienen en promedio 40 años de edad y las mujeres 44 años, lo cual indica que son mayores tomando en cuenta que la edad mínima de ellas es de 31 y la máxima 65 y para los hombres 25 y 57 años respectivamente (Ver Gráfica 1).

Gráfica 1. Distribución de la edad por género

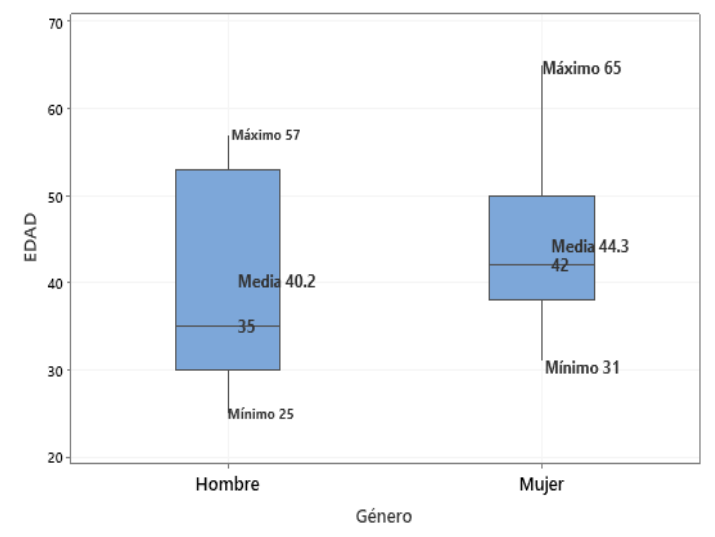

Fuente. Elaboración propia con datos de la encuesta

Para el estado civil, reportaron 58\% de las personas ser casadas y $42 \%$ solteras. Con respecto al porcentaje personas por estado civil y sexo, se encontró que tanto en los hombres como en las mujeres es mayor el porcentaje de casados (55\% y $60 \%)$, que de solteros (35\% y 40\%). Para el grado de estudios el $46 \%$ de la población entrevistada cuenta con una licenciatura, $27 \%$ con estudios de preparatoria y solamente el $4 \%$ con estudios de primaria.

En lo referente al producto que ofertan, se encontró que el número de hombres y de mujeres por rama artesanal, trabajan principalmente los derivados del café producto propio de la región, particularmente las mujeres en su mayoría se dedican a la rama textil, y los hombres, a los derivados del café como los licores, la confitería y la madera.

Los motivos para emprender de los artesanos encuestados, señalaron en el 73\% de los casos, el autoempleo y de manera complementaria la búsqueda de un ingreso adicional; y del sustento familiar.

El 50\% de los encuestados cuenta con otra fuente de ingresos adicional a la venta de artesanías. La mayoría (54\%) de las empresas artesanales del grupo de artesanos de Coatepec, tiene en el mercado una trayectoria de entre 3 a 10 años. Y únicamente el $8 \%$ dijeron tener, entre 1 y 2 años de vida, reflejando que son empresas de reciente creación que incursionan en el sector artesanal.

\subsection{Dimensiones de la variable Gestión Administrativa}

Las dimensiones que conformaron la variable fueron: 1) Estrategias administrativas generales; 2) Calidad e innovación del producto; 3) Gestión de mercadotecnia; 4) Recursos tecnológicos; 5) Competencia; 6) Gestión financiera y 7) Conocimiento del entorno. A continuación, se presentan los resultados de cada una de estas dimensiones.

En cuanto a las Estrategias

Administrativas Generales, que de acuerdo a lo que, Morales y Pech argumentan, concluyen que "la estrategia derivará en lineamientos o políticas de asignación de recursos con base en los objetivos y metas de la empresa, apoyándose en sus puntos fuertes $y$ en función de las características del medio ambiente" (Castañeda, Hernandez, \& Castro, 2008), se consideraron entonces, todas aquellas relacionadas con la forma en la que manejan el negocio, su visión futura y las acciones que llevan a cabo para su desarrollo empresarial, destacó la importancia otorgada por el $85 \%$ de los artesanos a buscar Ser una empresa conocida por su honestidad, respeto $y$ atención al cliente, reflejando con ello el valor que le dan al cliente. De la misma forma el $81 \%$ de ellos señaló Lograr ventas, que confirma que este tipo de negocios, generalmente son el sostén familiar.

Con relación a la visión futura, el $71 \%$ de los encuestados consideró muy importante Crecer a futuro, tanto en personal, como en capital y bienes, respuesta que señala una visión no solamente de permanecer sino también de desarrollo y crecimiento. También el 51\% mencionó Que este negocio permanezca toda la vida a través de las futuras generaciones familiares, reflejando la importancia de la familia en la visión futura de este tipo de empresas.

Otra estrategia practicada por el $88 \%$ de los artesanos, es la de Participar en exposiciones artesanales locales $y$ nacionales, hecho que confirma una de las características de las empresas artesanales de 
México que es la de dar a conocer sus productos a un mayor público o posibles clientes a través de ferias y exhibiciones de productos artesanales.

Otra de las estrategias más practicadas, por el $81 \%$ de los artesanos, es la de Ofrecer servicio de calidad al cliente, nuevamente indicando la importancia tanto de la calidad como de la atención al cliente.

Las siguientes dos estrategias practicadas por el $77 \%$ de los artesanos, fueron: Dar valor agregado a los productos como, por ejemplo: personalizarlos, un obsequio por compra, etc., y. Contar con una imagen formal en el mercado, es decir, tener una marca y logotipo establecido. Estrategias orientadas a mejorar las ventas y a darse a conocer en el mercado.

Cabe mencionar, algunas de las estrategias que muchos de los artesanos no practican (73\%), como, por ejemplo: Capacitar al personal, reflejando que no tienen personal contratado en sus empresas, ya que cuando requieren apoyo, generalmente hacen uso de familiares o amigos a quienes únicamente les asignan tareas de venta. También no forma parte de sus estrategias, cumplir con las obligaciones fiscales.

La dimensión de Calidad e Innovación del producto, fue considerada en especial dado que en las entrevistas del estudio cualitativo destacó como una estrategia a seguir relacionada con el producto. Más del $80 \%$ de los encuestados confirmaron la relevancia al señalar frases como: es muy importante: Que la calidad de mis productos satisfaga a mis clientes; o Buscar los mejores materiales para mis productos; El trato amable y con respeto en la atención a los clientes; o Prestar atención en los acabados y detalles en mis productos.

Estos resultados, reflejan la importancia primero, de satisfacer al cliente con el producto y con el servicio que le proporcionan, y segundo, la búsqueda de la calidad con el cuidado en los materiales, acabados y detalles del producto que ofrecen.

El 92\% de los artesanos dijeron que cuando los clientes están satisfechos con su producto lo demuestran recomendándolos con sus conocidos y regresando a comprarlos.
Con respecto a la innovación, el $73 \%$ dijo que Utilizar redes sociales para investigar las nuevas tendencias en el mercado, era una forma de lograr innovar su producto; seguido de un $69 \%$ de ellos, que lo que hacen es Buscar constantemente información para tratar de innovar en los productos y Les gusta a los artesanos crear productos que no existan en ningún otro lugar, entendiendo sin lugar a dudas que los artesanos requieren estar en la búsqueda constante de información que les permita analizar lo que sucede en el mercado para poder hacer innovaciones.

En la innovación de algún producto, es importante considerar los tiempos en los que se pueden hacer esas mejoras o cambios, para considerarlo en los planes y estrategias de las empresas, de acuerdo a las respuestas, se observa que en el $50 \%$ de los casos, los procesos de innovación se dan Por temporadas, aunque el $31 \%$ de los artesanos dijeron que No tienen un tiempo definido y un $23 \%$ señalaron que tratan de innovar de acuerdo a modas y tendencias.

Hoy en día, más que en otros momentos de la vida, las empresas deben poner en práctica estrategias de mercado eficaces que les ayuden a ganar presencia en el mismo y en la preferencia de los clientes que haga negocios competitivos, en un mercado tan variado y globalizado. El éxito financiero a menudo depende de la habilidad de marketing (Kotler, Kartajaya, \& Setiawan, Marketing 4.0, 2016).

De aquí la importancia de la Gestión de mercadotecnia, que realizan los artesanos encuestados, el $73 \%$ de ellos, le dieron mucha importancia, al: Uso de redes sociales, seguido del $65 \%$ que eligió: Establecimiento de marca y logotipo; y Uso de tarjetas de presentación, como las estrategias más practicadas.

También fue importante destacar las estrategias a las que los artesanos no les dan importancia como: Impresión de volantes; Uso de página Web para vender mis productos; y Publicidad local (es decir, por medio de volantes, carteles, radio, etc).

Para comprender las causas por las cuales no hacen uso de las estrategias de 
mercadotecnia, se pidió a los artesanos expresaran sus motivos las respuestas obtenidas en la que No tengo el dinero para invertir en eso, No sé cómo hacerlo; y Mi empresa ha funcionado sin practicar ninguna de esas estrategias, fueron los motivos señalados por poco más de la tercera parte de los encuestados.

$\mathrm{Al}$ estar frente a un mundo globalizado en el que la tecnología cada vez avanza más y exige a las empresas adaptarse a ella, los Recursos tecnológicos, se han vuelto una necesidad y por tanto para la gestión administrativa de estas empresas artesanales más del $80 \%$ de los encuestados, dijeron usar siempre el Smartphone (celular), y el Internet.

Las razones de poco más del $30 \%$ de los artesanos para justificar no utilizar recursos tecnológicos fueron: No cuento con ese recurso; No se usar muy bien el recurso tecnológico; y No cuento con recursos económicos para comprarlos.

Considerada como "la rivalidad entre empresas que participan en un mercado, aplicando sus mejores estrategias de manera que pueden minimizar sus costos, maximizar sus ganancias y así mantenerse activas e innovadoras frente a otras empresas rivales" (citado por Sandoval, 2011 en (Gutiérrez, 2013, pág. 26)), la Competencia y el conocimiento que el responsable de una organización tiene de ésta, es muy importante hoy en día, estudiarla o tenerla identificada para tomar decisiones acerca de la manera en la que puede utilizarla como oportunidad de mejora o crecimiento en lugar de verla como una desventaja para el cumplimiento de objetivos y metas, esta es la manera en la que los artesanos perciben la competencia a través de una pregunta abierta en la que se les solicitó su opinión.

En la siguiente Imagen, se resumen las palabras asociadas a las respuestas que dieron los artesanos de Coatepec, y se puede observar que la mayoría consideran a la competencia como una oportunidad de mejorar, de innovar, de desarrollar su creatividad, de ofrecer mejor calidad, de dar un mejor servicio, en pro de crecer y ganar preferencia del cliente, esto con base en las diferentes respuestas obtenidas.
Imagen 1. Nube de palabras para las opiniones acerca de la competencia

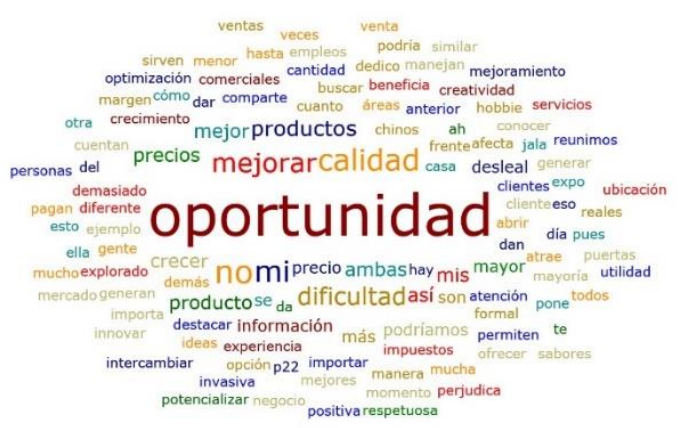

Fuente. Elaboración propia con datos de la encuesta

Sin embargo, también algunos de los encuestados señalaron a la competencia desleal de productos chinos como una dificultad, debido a las características de calidad y de precios, que afectan las ventas directamente, o la competencia de organizaciones de mayor tamaño, y mostraron poco interés por establecer alianzas o asociaciones entre ellos.

Uno de los grandes desafíos en el funcionamiento y operación de todo tipo de empresa, es el de lograr administrar y gestionar de la mejor manera los recursos financieros (Gestión financiera).

Como parte de las estrategias de la gestión financiera que las empresas artesanales, ponen en práctica más del 50\% de los artesanos, mencionaron: Conocer la ganancia de sus productos; Tener registro de sus ventas y el Control de ingresos y gastos.

Las estrategias menos practicadas por los artesanos son el Llevar contabilidad de sus negocios y Tener contador.

Con relación a la formalidad de los negocios artesanales, el $38 \%$ de los artesanos que respondieron el cuestionario, están formalmente registrados ante las autoridades correspondientes, mientras que el $62 \%$ no lo están; algunas de las razones por las cuales no se encuentran en esa situación legal son: $l a$ falta de conocimientos en el tema, el no querer pagar impuestos, y la falta de recursos o el pensamiento de considerase un negocio pequeño para poder hacerlo.

Mientras que el porcentaje que mencionó encontrarse formalmente registrado, dijo que lo hicieron, porque esto les trae muchos beneficios como ganar más 
clientes, y tener otro tipo de oportunidades, y también porque lo consideran como una obligación y como una ventaja a su imagen.

Tradicionalmente el entorno de la empresa se divide en dos grandes grupos: específico y general. El entorno específico, afecta de modo especial a la empresa, y es más cercano. El entorno general, afecta a todas las empresas, y no lo hace de modo tan directo. (Medrano, 2008)

En este trabajo de investigación el Conocimiento del entorno se refiere a todas aquellas situaciones externas que afectaban positivamente o negativamente la actuación de las empresas artesanales en el mercado. Para su desarrollo y análisis, se tomaron en cuenta también aquellos efectos de la pandemia del Covid-19 que, sin lugar a dudas, tuvieron lugar en las empresas objeto de estudio y que sucedió durante el desarrollo del proyecto.

Las principales limitantes señaladas fueron: la Falta de valor para las artesanías por parte del cliente; y la Falta de apoyo por parte de autoridades municipales (ambas con el $56 \%$ ), así como; la falta de créditos financieros y la competencia desleal (Ver Tabla 1).

Tabla 1. Limitantes de las empresas artesanales

\begin{tabular}{|l|c|c|}
\hline Limitante & Número & $\%$ \\
\hline $\begin{array}{l}\text { Falta de valor para las artesanías } \\
\text { por parte del cliente }\end{array}$ & 14 & $56 \%$ \\
\hline $\begin{array}{l}\text { Falta de apoyo por parte de } \\
\text { autoridades municipales }\end{array}$ & 14 & $56 \%$ \\
\hline La competencia desleal & 10 & $40 \%$ \\
\hline Falta de créditos financieros & 10 & $40 \%$ \\
\hline Difícil aceptación del mercado & 5 & $20 \%$ \\
\hline Creciente competencia & 5 & $20 \%$ \\
\hline
\end{tabular}

En la Tabla 2, se muestra que el $85 \%$ de los artesanos señalaron como ventaja de esta actividad, la oportunidad del Emprendimiento con habilidades manuales y creativas, seguido de Las artesanías son un producto tradicional y representativo del país y esto les genera una imagen corporativa favorable.

Adicionalmente consideraron como ventajas, el beneficio de la identidad cultural que reflejan, así como también la zona geográfica en donde se ubiquen, en este caso, las empresas son originarias, productoras y vendedoras en Coatepec, y esta ciudad, forma parte de los pueblos mágicos del país, lo que genera un valor agregado a una zona valorada.

Tabla 2. Ventajas de las empresas artesanales

\begin{tabular}{|l|c|c|}
\hline Ventaja & Número & $\%$ \\
\hline $\begin{array}{l}\text { Emprendimiento con habilidades } \\
\text { manuales y creativas }\end{array}$ & 22 & $85 \%$ \\
\hline $\begin{array}{l}\text { Las artesanías son un producto } \\
\text { tradicional y representativo del país }\end{array}$ & 21 & $81 \%$ \\
\hline Zona geográfica valorada & 17 & $65 \%$ \\
\hline $\begin{array}{l}\text { Reforzamiento de la identidad } \\
\text { cultural }\end{array}$ & 17 & $65 \%$ \\
\hline Autoempleo & 16 & $62 \%$ \\
\hline Otros & 1 & $4 \%$ \\
\hline
\end{tabular}

A pesar de que al inicio del proyecto no se tenía considerado, fue relevante diseñar preguntas relacionadas con los efectos que la pandemia Covid-19 estaba ocasionado en las empresas artesanales encuestadas.

El tema se abordó en el estudio cuantitativo, mediante dos ítems, en el primero resultado del estudio cualitativo, se ofrecieron opciones para elegir por parte del encuestado como respuesta al cuestionamiento ¿Cuáles de los siguientes casos te han ocurrido a ti y a tu empresa artesanal durante y con la pandemia del COVID 2019? (puedes marcar varias opciones); en el segundo, se les dedicó una pregunta abierta para que señalaran efectos positivos y negativos de su negocio ante dicha pandemia.

Con relación a la primera pregunta, en la Tabla 3, se puede observar los mayores efectos que ha causado la pandemia en las empresas artesanales de Coatepec, el 66\% de ellos dijo que Recurrir a otra fuente de ingresos para poder mantenerse, seguido de Recurrir únicamente a venta en línea $(58 \%) \mathrm{y}$ en tercer lugar el Obtener pérdidas en lugar de ganancias (46\%).

Estos efectos son situaciones que muchas empresas en el país han sufrido a consecuencia de la pandemia, y alcanzaron a afectar también a los artesanos de Coatepec provocando la cancelación de días de venta en el espacio con el que contaban y por tanto, la 
afectación en los ingresos.

Cabe mencionar que de los siete que mencionaron que sus ventas aumentaron, seis de ellos manifestaron que después de haber hecho uso de la tecnología y únicamente uno de ellos, dedicado al diseño, dijo que debido a las características de su producto, el mismo encuestado dijo que todo era igual que antes de la pandemia.

Tabla 3. Efectos pandemia Covid-19

\begin{tabular}{|l|c|c|}
\hline Efecto & Número & $\%$ \\
\hline $\begin{array}{l}\text { Recurrir a otra fuente de ingresos } \\
\text { para poder mantenerte }\end{array}$ & 16 & $62 \%$ \\
\hline $\begin{array}{l}\text { Recurrir únicamente a venta en } \\
\text { línea }\end{array}$ & 15 & $58 \%$ \\
\hline $\begin{array}{l}\text { Obtener pérdidas en lugar de } \\
\text { ganancias }\end{array}$ & 12 & $46 \%$ \\
\hline $\begin{array}{l}\text { Mis ventas han aumentado aún } \\
\text { más durante estas fechas }\end{array}$ & 7 & $27 \%$ \\
\hline Depresión y/o problemas de salud & 2 & $8 \%$ \\
\hline $\begin{array}{l}\text { Todo ha sido igual que antes de la } \\
\text { pandemia }\end{array}$ & 1 & $4 \%$ \\
\hline $\begin{array}{l}\text { Fuente. Elaboración propia. No suma } \\
\text { elegirse más de una opción. } \\
\text { Respecto a las porque podía }\end{array}$ \\
\hline
\end{tabular}

proporcionadas de los artesanos encuestados en la pregunta abierta acerca de los efectos positivos y negativos de la pandemia, en la Tabla 4, se muestra un resumen de coincidencias de las respuestas dadas por los artesanos, en los que se pueden observar efectos positivos y negativos.

Positivos en cuanto a llevar a las empresas a adaptarse a la tecnología y la nueva forma de ofrecer sus productos en línea para poder generar ventas, también el tener que buscar nuevos puntos de venta, buscar nuevos productos que ofrecer y salir de la zona de confort.

Efectos negativos principalmente se observan en la reducción de ventas hasta en un $70 \%$, el recurrir a otro tipo de negocios para poder mantenerse, la cancelación de espacios para vender sus productos y también la falta de turismo a la ciudad, son consecuencias que ha dejado en las empresas artesanales de la ciudad la pandemia.

A finales de diciembre del 2020, la venta en bajos del palacio municipal se reanudó con todas las medidas de seguridad pertinentes, y esperando buenas ventas y respuestas por parte del consumidor para poder, equilibrar lo causado en los meses anteriores.

Tabla 4. Resumen de opiniones de artesanos de Coatepec respecto a la pandemia del Covid-19

\begin{tabular}{|l|c|c|}
\hline Resumen de opiniones & Número & $\mathbf{\%}$ \\
\hline Se ha adaptado a la tecnología & 8 & $31 \%$ \\
\hline Ha afectado de manera positiva & 5 & $19 \%$ \\
\hline Se ha visto reducida la venta & 5 & $19 \%$ \\
\hline $\begin{array}{l}\text { Ha tenido efectos positivos y } \\
\text { negativos }\end{array}$ & 2 & $8 \%$ \\
\hline $\begin{array}{l}\text { Fue necesario recurrir a nuevos } \\
\text { productos }\end{array}$ & 2 & $8 \%$ \\
\hline Sin comentarios & 2 & $8 \%$ \\
\hline $\begin{array}{l}\text { Se tuvo que mantener el } \\
\text { producto }\end{array}$ & 1 & $4 \%$ \\
\hline Recurrir a otros empleos & 1 & $4 \%$ \\
\hline Total general & $\mathbf{2 6}$ & $\mathbf{1 0 0 \%}$ \\
\hline
\end{tabular}

Fuente. Elaboración propia

Con el interés de ampliar un poco más los resultados del efecto de la pandemia en los artesanos de Coatepec, a continuación se exponen los resultados acerca de este tema obtenidos de las entrevistas llevadas a cabo en el estudio cualitativo cuyas expresiones de mayor relevancia se muestran en la Red de citas de la Figura 1:

El esfuerzo y perseverancia de estos artesanos al tratar de salir adelante a pesar de las situaciones adversas a ellos con sus negocios no ha desfallecido, al contrario, ha aumentado con el motivo de salir adelante, lo que consideran como la actitud correcta para vencer los obstáculos.

“...nos podemos adaptar a las normas que nos pidan con tal de vender al cliente"

"...ahorita con el Covid, yo no he vendido ya llevo como cinco meses sin trabajar en eso, pero realmente aquí estoy produciendo"

"...al principio de la pandemia igual tuve una actitud de que dije pues ya a ver qué hago porque no se va a vender nada, pero pues un día dije voy a publicar y empezar, voy a intentarlo, y vi pues que sí había dinero y me funcionaba, y pues yo creo que si yo me hubiera quedado con esa actitud, pues yo creo que no siguiera con esto"

Alguno de los artesanos entrevistados, se superó esforzándose más en el uso de sus redes sociales para poder vender, también decidió hacer entregas a domicilio dentro de 
la ciudad y ha tenido buenos resultados.

“... yo tuve esa actitud al principio y quizás a muchos les dio depresión y así, y si yo me hubiera quedado con esa actitud pues me hubiera ido para abajo, pero al contrario empecé a implementar entregas a domicilio y hasta me compré mi bicicleta para facilitar eso y dar el envío a domicilio más barato, entonces yo creo que depende de la persona"

Otro artesano entrevistado, tuvo que recurrir a la venta de otro tipo de producto para poder sostenerse, ya que, muchos de ellos, se dedican $100 \%$ al negocio artesanal, ahora vende también plantas carnívoras.

“....ahorita que está lo del Covid, cambiaron un poco las circunstancias, vendo plantas carnívoras por Internet"

Comentan los artesanos, que la competencia en estos meses de pandemia aumentó, porque como muchas otras personas perdieron empleos, recurrieron a actividades manuales para trabajar.

“... ahorita con la pandemia, como muchos perdieron sus trabajos y decidieron emprender, entonces cada vez hay más personas que venden lo mismo que yo"

La importancia de incursionar en redes sociales y en la venta en línea fue un factor determinante para la permanencia de los artesanos.

“...ahora en la pandemia, mi página subió un buen de seguidores, y me ha ido muy bien".

"... ahorita en la pandemia a muchos lo que les ayudó fue eso, moverse en redes sociales, pero te digo, muchos no lo hicieron porque no saben usarlas"

Desde la perspectiva de los entrevistados, varios de los compañeros del grupo de artesanos cerraron sus negocios por la falta de ventas e inclusive uno de ellos falleció por enfermedad del Covid-19, sin embargo, también algunos mejoraron gracias a las redes sociales.

“...ahorita en la pandemia muchos cerraron, pero entonces igual muchos hasta abrieron otro local porque con redes sociales despuntaron"

Las esperanzas están vivas en los artesanos entrevistados con relación a que se pueda regresar a vender para poder ayudarse económicamente, atendiendo a todos los protocolos de seguridad. Piensan que la gente apoyará al negocio artesanal al consumir sus productos.

“...yo creo que la gente tiene ganas de regresar a la vida normal y ver las artesanías, va a haber algo que les guste, entonces yo creo que eso nos ayuda mucho y sí va a haber venta tal vez no como la que quisiéramos pero si vamos a tener un buen recibimiento, porque pues también la gente es solidaria"

“...el factor en contra es el dinero, pero hay mucho turismo"

Entre otros efectos, estos fueron los más sobresalientes de lo comentado por los artesanos entrevistados.

El análisis cuantitativo de este trabajo de investigación, proporcionó información sumamente importante y relevante para comprender la situación de las empresas artesanales de Coatepec, y conocer cuáles son los factores de la gestión administrativa que ellas ponen en práctica y que les han ayudado a permanecer en el mercado.

\section{CONCLUSIONES}

El estudio cualitativo permitió contextualizar y modelar la manera en que se desenvuelve la gestión administrativa en este grupo de artesanos de la ciudad de Coatepec, Veracruz, México. Con esto, se tuvo información que fundamentó el estudio cuantitativo llevado a cabo mediante encuesta a 26 artesanos del mencionado grupo.

De la información analizada cuantitativamente, se confirmaron los resultados del estudio cualitativo, pero también se adicionaron aspectos de interés que se resumen en los siguientes párrafos:

En cuanto a los datos sociodemográficos, no se encontró diferencias en cuanto al género, sin embargo, se halló que las mujeres tienen mayor edad que los hombres. En su mayoría, tanto hombres como mujeres son casados. El nivel de estudios que más del $40 \%$ de los encuestados señalaron fue el de licenciatura y únicamente el $4 \%$ dijo tener estudios de primaria.

Con relación a los productos que ofrecen, la mayoría utiliza los derivados del café que es un producto de la región. Las 
mujeres se dedican más a la elaboración de textiles y los hombres a los derivados del café como los licores, la confitería y la madera.

El autoempleo es el motivo señalado por la mayor parte de los encuestados para su emprendimiento como artesanos y en general la búsqueda de mayores ingresos para el sustento familiar.

La mayoría de artesanos ha permanecido en el mercado entre tres y diez años, lo que indica una permanencia superior a la señalada como esperanza de vida de 6 años para el Estado de Veracruz (PYMES Consulting, 2019). 
Figura 1. Red de citas para el Código EFECTOS PANDEMIA

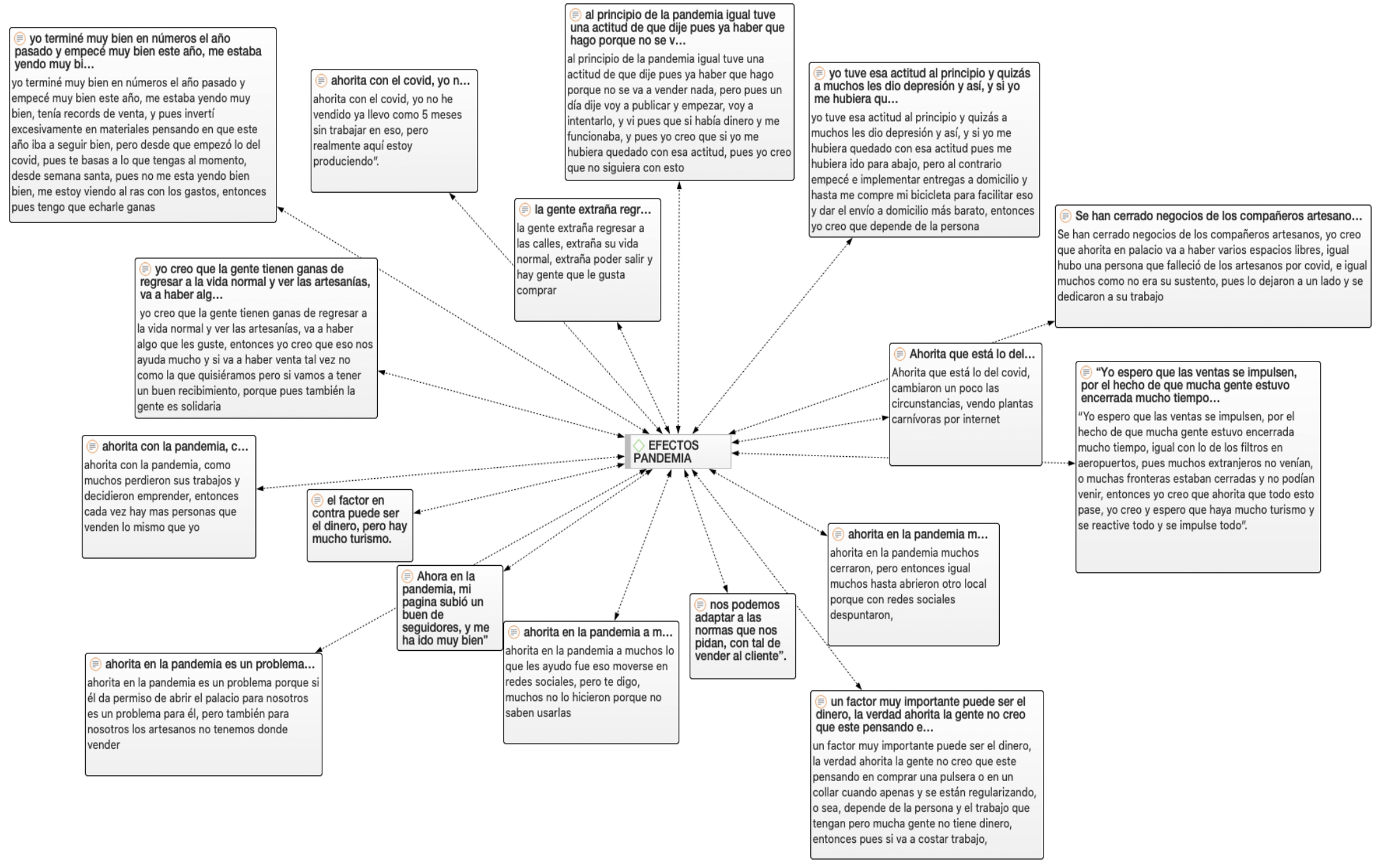

Fuente. Elaboración propia 
Aspectos relevantes de la Gestión Administrativa y de las dimensiones consideradas en el estudio, se presentan en las siguientes gráficas.

En la Gráfica 2, se presentan las estrategias administrativas generales utilizadas por los encuestados en la cuales se identifica su visión como negocio y las acciones a las que les otorgan mayor importancia para su desarrollo como organización.

Cabe mencionar que en el aspecto de los recursos humanos generalmente acuden a familiares y amigos para la contratación y por ello no ofrecen capacitación, solamente asignan tareas para la venta.

Gráfica 2.Estrategias administrativas generales

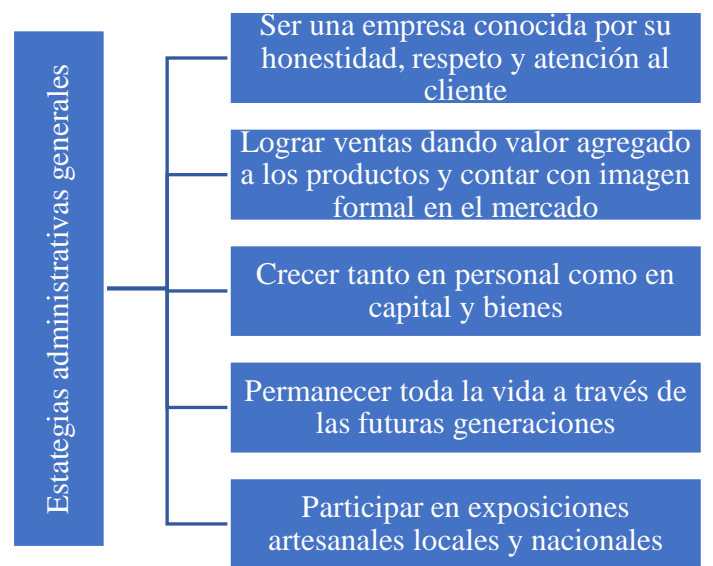

Fuente. Elaboración propia

Por su parte la Calidad e Innovación del producto resultó una dimensión a la que los artesanos atribuyeron gran importancia para su permanencia en el mercado. Las gráficas 3 y 4 muestran por separado las acciones que realizan para cada una de ellas, y en las que la calidad del producto tiene como eje central la satisfacción del cliente y en cuanto a la innovación la búsqueda permanente de información de tendencias y modas como fundamento.
Gráfica 3. Calidad del producto

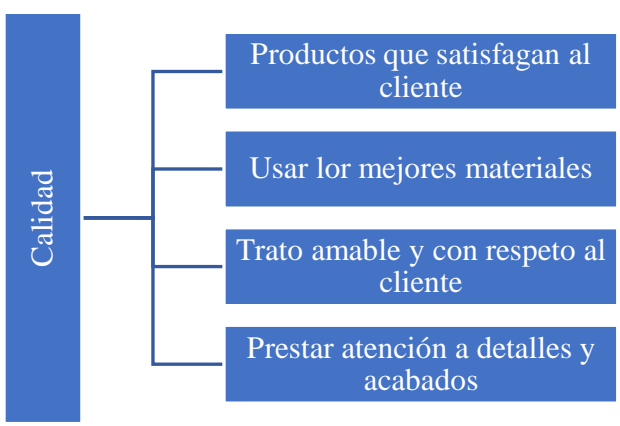

Fuente. Elaboración propia

Gráfica 4. Innovación del producto

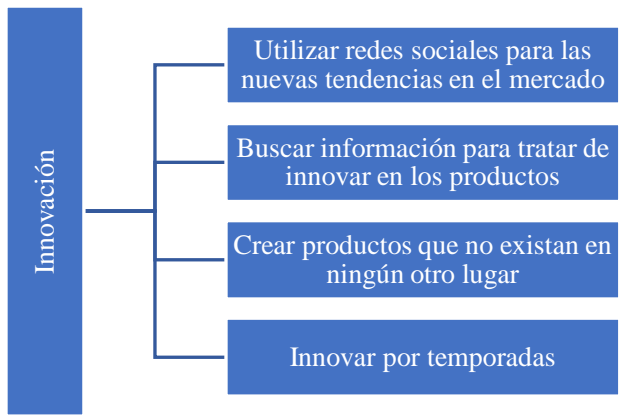

Fuente. Elaboración propia

A continuación se describen en la Gráfica 5, las estrategias que desarrollan los artesanos encuestados para darse a conocer en el mercado al que atienden. Destaca el uso de redes sociales, sin embargo, no usan páginas Web propias, ni medios masivos como radio o televisión debido a que no cuentan con recursos o consideran que no es necesario.

Gráfica 5.Gestión de Mercadotecnia

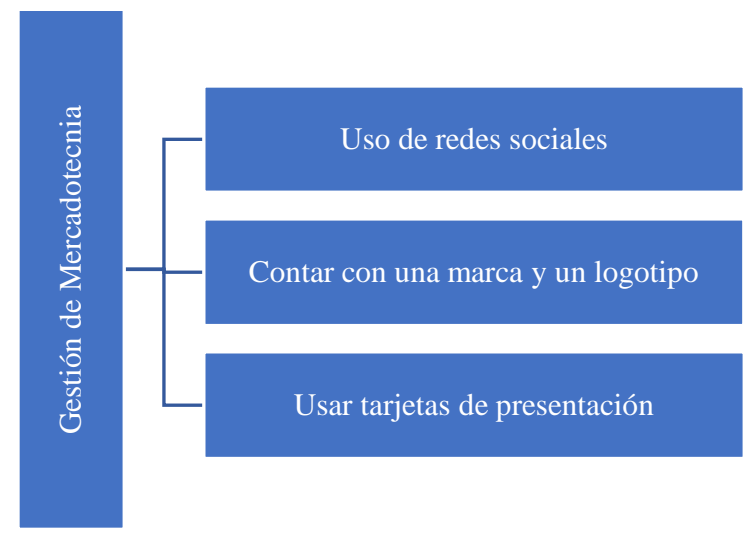

Fuente. Elaboración propia

Los Recursos tecnológicos más usados fueron el celular (Smartphone) y el Internet, sin embargo, están conscientes de que podrían tener otras opciones, pero carecen de 
conocimientos o de recursos económicos para implementarlos (Ver Gráfica 6).

Gráfica 6. Recursos tecnológicos

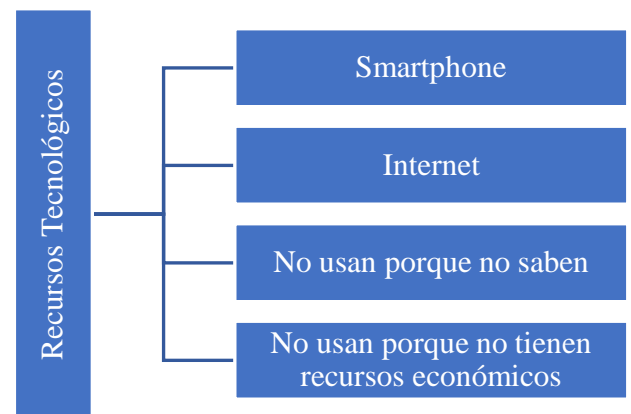

Fuente. Elaboración propia

Un aspecto que se comprobó en este estudio fue la relevancia de la competencia, referida al conocimiento que tienen los artesanos de los oferentes de productos similares a las artesanías (Gráfica 7). Y aunque en su mayoría la consideraron una oportunidad, también fue señalada como una de las limitantes de mayor importancia para ellos.

\section{Gráfica 7. Competencia}

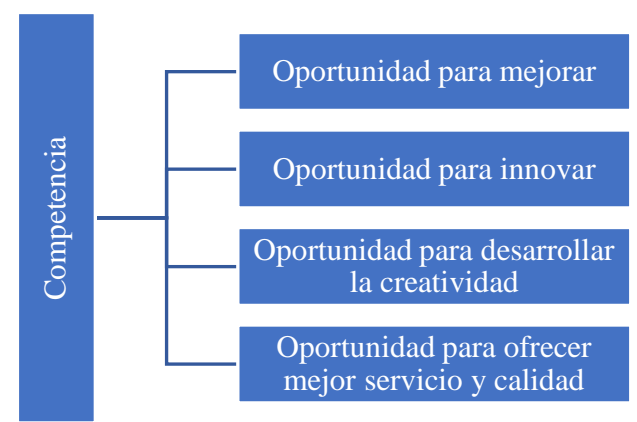

Fuente. Elaboración propia

Aunque saben la importancia del control y registro de los recursos financieros, solamente realizan un control de ellos en cuanto a ingresos y gastos, registro de ventas y análisis para conocer ganancia, pero no se encuentran interesados en tener un contador o en registrarse formalmente ante el fisco por diversos motivos principalmente económicos (Ver Gráfica 8).
Gráfica 8. Gestión Financiera

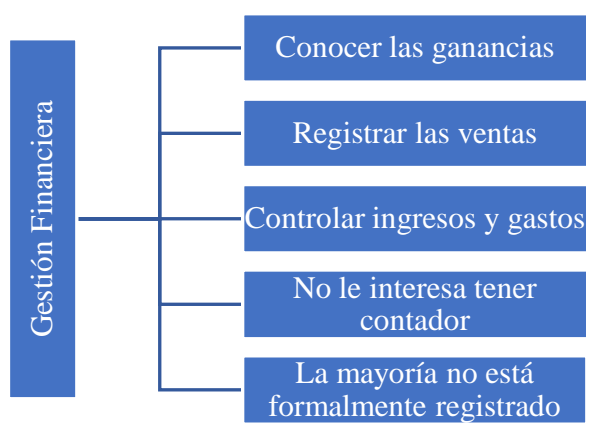

Fuente. Elaboración propia

El conocimiento del entorno es la última dimensión estudiada y se refirió a las situaciones externas a la organización que suelen impactarlas favorable o desfavorablemente.

En la Gráfica 9 se resumen tanto las limitantes y en la Gráfica 10, las ventajas atribuidas por los artesanos al entorno.

Fue interesante encontrar que la pandemia que aún se vive actualmente, ha hecho que los artesanos busquen opciones para resolver su situación de emprendimiento. Las dos de mayor relevancia han sido la venta en línea y buscar otro empleo para subsistir.

Gráfica 9. Conocimiento del entorno (limitantes)

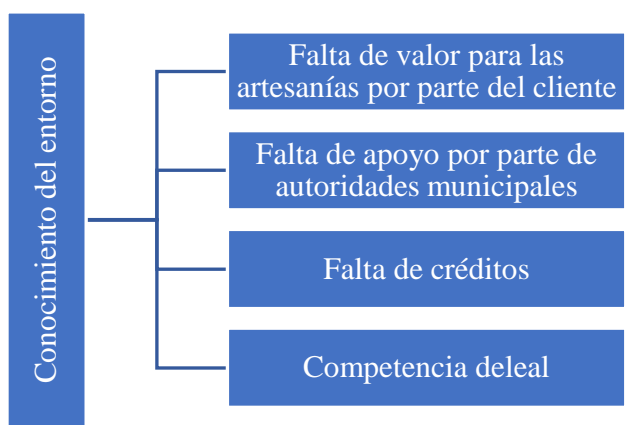

Fuente. Elaboración propia

Gráfica 10. Conocimiento del entorno (Ventajas)

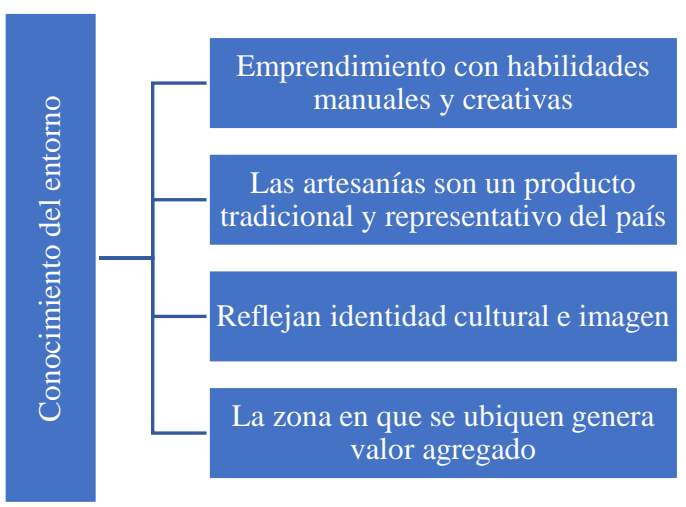


Fuente. Elaboración propia

El marketing digital hoy en día se ha convertido en una necesidad para las empresas de todo tipo de tamaño, dejando de ser una opción si se pretende ser una empresa competitiva en el mercado, por lo que se recomienda a las empresas artesanales, continuar con las estrategias que han practicado con relación a su imagen, publicidad y venta en línea a través de redes sociales, pero también implementar la venta a través de páginas Web propias o en plataformas a su disposición. Por tanto, deben capacitarse en aspectos de las tecnologías de la información y de su aplicación.

A manera de cierre de este trabajo, se puede señalar que los resultados obtenidos pueden seguir siendo sustento y base para futuros estudios en los que se profundice a un nivel mayor en cada uno de los factores de la gestión administrativa identificados en las empresas artesanales de Coatepec, diseñando con ello, acciones administrativas generalizadas en apoyo de las empresas de este sector tan importante para México. 


\section{REFERENCIAS}

Castañeda, J. J., Hernandez , M. D., \& Castro, C. M. (2008). Estrategias y competitividad de los negocios de artesanía en México. Pensamiento \& Gestión. Obtenido de https://www.redalyc.org/articulo.oa?id=64612291008

Lopez, P. A., \& Arevalo, A. M. (2010). Hacia una evolución en el campo del conocimiento de la disciplina administrativa de la administración de empresas a la gestión de organizaciones. Facultad de Ciencias Ecnómicas Volumen XVIII, 75-93.

Luna, F. H., Salgado, A. V., Cuevas, B. G., \& Barrios, G. R. (2016). Ciclo de Vida Organizacional en las MiPymes Mexicanas, Ramo Maderero. Revista de Negocios \& PYMES, 1-8. Obtenido de

https://www.ecorfan.org/spain/researchjournals/Negocios_y_PyMES/vol2num4/Revista_de_ Negocios_\&_PYMES_V2_N4_1.pdf

El Economista. (4 de Marzo de 2018). Artesanías, muy importantes para México. Obtenido de El Economista: https://www.eleconomista.com.mx/opinion/Artesanias-muy-importantes-paraMexico-20180304-0066.html

Gutiérrez, C. G. (2013). La competencia empresarial y su apicabilidad . Memorias del II congreso Binacional de Investigación, Ciencia y Tecnología de las Universidades , 25-41.

INEGI, FONART \& SEDESOL. (2018). Artesanos y artesanías, una perspectiva económica. Obtenido de FONART: https://www.gob.mx/cms/uploads/attachment/file/330994/ARTESANOS_Y_ARTESANIAS _UNA_PERSPECTIVA_ECONOMICA.pdf

Kotler, P., Kartajaya, H., \& Setiawan, I. (2016). Marketing 4.0. Perú: Asociación Peruana de Estudiantes de Marketing APEM - Escuela de Marketing.

Medrano, E. (2008). La empresa y su entorno, Unidad 1. Obtenido de https://www.edebe.com/educacion/documentos/830343-0-529-830343_LA_EIE_CAS.pdf

Méndez, F. (24 de Septiembre de 2019). México, el sexto país más visitado del mundo (y sus lugares más populares). Obtenido de Travesías: México, el sexto país más visitado del mundo (y sus lugares más populares)

PYMES Consulting . (13 de 07 de 2019). PYMES Consulting. Obtenido de PYMES Consulting, conectamos todos los puntos : https://www.pymes.consulting/blog/cual-es-la-expectativa-devida-de-una-pyme-mexicana-al-nacer 